LUCIANE MARTINS

\title{
A Galectina-3 na Fisiologia E no CÂnCER de Tiróide: IDENTIFICAÇÃO DE SNPS NO GENE LGALS3 E ESTUDO FUNCIONAL DE GaLECTINA-3 IN VITRO E IN VIVO
}

Tese (Doutorado) apresentada ao Instituto de Ciências Biomédicas da Universidade de São Paulo, para obtenção do Título de Doutor em Ciências (Biologia Celular e Tecidual).

Área de concentração:

Biologia Celular e Tecidual

Orientador:

Profa. Dra. Edna Teruko Kimura

São Paulo

2008 


\section{RESUMO}

Martins L. Galectina-3 na Fisiologia e no Câncer de Tiróide: Identificação de SNPs no Gene LGALS3 e Estudo Funcional de Galectina-3 in Vitro e in Vivo [Tese]. São Paulo: Instituto de Ciências Biomédicas da Universidade de São Paulo; 2008.

A galectina-3 é uma proteína monomérica de 30kDa que apresenta uma alta expressão no câncer de tiróide, no entanto, a função especifica desta proteína na tumorigênese da tiróide não é conhecida. Para investigar o envolvimento de galectina-3 na fisiologia e no câncer de tiróide usamos vários modelos biológicos e metodologias. A presença de SNPs nos códons 64, 98, 183 e 201 do gene $L G A L S 3$ foi identificada em tumores benignos e malignos de tiróide por seqüenciamento de DNA. No entanto, a avaliação detalhada do SNP no códon 98 (T98P) por método de Polimorfismo Conformacional de Fita Simples (SSCP) mostrou que o genótipo deste SNP não está correlacionado com fenótipo de tumor benigno ou maligno da tiróide. A indução condicional da expressão do oncogene RET/PTC na linhagem celular de tiróide de rato $\mathrm{PCCl} 3$ aumenta a expressão gênica de galectina-3, sugerindo um envolvimento desta proteína nos eventos iniciais da tumorigênese da tiróide. No entanto, quando somente a expressão de galectina-3 é induzida na linhagem PCCl3 nenhum aumento na proliferação celular e transformação da célula é observado, sugerindo que galectina-3 não é um fator oncogênico. Na linhagem de carcinoma papilífero de tiróide TPC-1, que apresenta o oncogene RET/PTC endógeno, o silenciamento pós-transcricional de galectina-3 por método de interferência de RNA mostra que: 1) a galectina-3 contribui para a sobrevivência da célula tumoral e progressão do ciclo celular, aumentando a expressão de c-Myc e diminuindo a expressão de p21 e caspase-3; 2) a galectina-3 se liga à $\beta$-catenina e coopera na transcrição de genes alvos da sinalização WNT/ $\beta$-catenina (MYC e $C C N D 1)$; 3) a galectina-3 aumenta a fosforilação das proteínas ERK e AKT, colaborando na ativação sustentada de importantes vias de sinalização que estão envolvidas no controle da expressão, estabilidade e função de reguladores do ciclo celular. Na linhagem celular $\mathrm{PCCl} 3$ observamos que a galectina-3 aumentou a atividade do promotor do gene $T g$ por ensaios de gene repórter, mas este efeito é perdido quando a via de sinalização WNT/ $\beta$-catenina é ativada constitutivamente. Por outro lado, na linhagem celular de carcinoma cervical HeLa a galectina-3 atenua a atividade do promotor do gene $T g$ que é induzida pelo fator de transcrição TTF-1. Uma vez que não detectamos ligação entre galectina-3 e TTF-1, sugerimos que o efeito de galectina-3 na transcrição de $T g$ é um efeito indireto e depende do contexto celular. In vivo, a avaliação histomorfológica e imunohistoquímica da tiróide de camundongos tratados com droga 
bociogênica mostra que camundongos knockouts para galectina-3 $\left(\mathrm{Gal}^{-/-}\right)$respondem ao tratamento promovendo uma redução mais acentuada no lúmen folicular tiroidiano e um aumento menor na expressão de tireoglobulina do que camundongos selvagens $\left(\mathrm{Gal}^{+/+}\right)$. Concluímos que a galectina-3 contribui para a progressão do ciclo celular e sobrevivência da célula tumoral e interfere na diferenciação da célula folicular tiroidiana.

Palavras-chave: Tiróide, Câncer de tiróide, Galectina-3, LGALS3, $\beta$-catenina, Ciclina D1, c-Myc, p21, p27, MAPK, AKT, PI3K, WNT, TTF-1, PAX-8, Tireoglobulina, Interferência de RNA, Knockout para galectina-3, Gene repórter, Ensaio de interação proteína-proteína, Polimorfismo de um único nucleotídeo, Seqüenciamento e Polimorfismo conformacional de fita simples. 


\begin{abstract}
Martins L. Galectin-3 in Thyroid Physiology and Cancer: Identification of SNPs in the LGALS3 gene and functional study of galectin-3 in Vitro and in Vivo [PhD thesis]. São Paulo: Biomedical Science Institute, University of São Paulo; 2008.
\end{abstract}

Galectin-3 is a $30 \mathrm{kDa}$ monomeric protein highly expressed in thyroid cancer, however, its specific function in thyroid tumorigenesis is unknown. To investigate the involvement of galectin-3 in thyroid physiology and cancer several biological models and methodologies were employed. The presence of SNP in codon 64, 98, 183 and 201 of the LGALS3 gene was identified in benign and malignant thyroid tumors by DNA sequencing. Nevertheless, a detailed evaluation of SNP on codon 98 (T98P) by the single-strand conformation polymorphism method showed that the T98P genotype is not correlated with the phenotype of benign or malignant thyroid tumors. The conditional induction of RET/PTC oncogene expression in the rat thyroid cell line $\mathrm{PCCl} 3$ increases the galectin-3 gene expression, suggesting involvement of this protein in the early events in thyroid tumorigenesis. However, when only the galectin-3 expression is induced in the $\mathrm{PCCl} 3$ cell line no increase in cell proliferation and cell transformation is observed, suggesting that galectin-3 is not an oncogenic factor. In the papillary thyroid carcinoma cell line TPC-1 which presents the RET/PTC oncogene, the post-transcriptional silencing of the galectin- 3 gene by the RNA interference method shows that: 1) galectin-3 contributes to tumor cell survival and cell cycle progression, increasing c-Myc expression and decreasing p21 and caspase-3 expression; 2) galectin-3 binds to $\beta$-catenin and cooperates in transcription of $\mathrm{WNT} / \beta$-catenin signaling target genes (MYC and CCND1); 3) galectin-3 increases the phosphorylation of ERK and AKT proteins, collaborating in activation of important signaling pathways involved in the control of expression, stability and function of cell cycle regulators. In the PCCl3 cell line, we observed that galectin-3 increased the $T g$ promoter activity using the reporter gene assay, but this effect is abolished when the WNT/ $\beta$-catenin signaling pathway is constitutively activated. In contrast, in the HeLa cervical carcinoma cell line galectin-3 attenuates $\mathrm{Tg}$ promoter activity which is induced by transcription factor TTF-1. Since we did not detect binding between galectin-3 and TTF-1, we suggest that the effect of galectin-3 in $T g$ transcription is an indirect effect and depends on cellular context. In vivo, the histomorphological and immunohistochemical evaluation of mice thyroid treated with goitrogenic drugs shows that galectin-3 knockout mice respond to treatment promoting more accentuated reduction in follicular lumen and lower increase in thyroglobulin expression than 
wild-type mice. In conclusion, galectin-3 contributes to cell cycle progression and tumor cell survival and interferes in the differentiation of thyroid follicular cell.

Keywords: Thyroid, Thyroid cancer, Galectin-3, LGALS3, Single Nucleotide Polymorphism (SNP), $\beta$ catenin, Cyclin D1, c-Myc, p21, p27, MAPK, AKT, PI3K, WNT, TTF-1, PAX-8, Thyroglobulin, RNA interference (RNAi), Galectin-3 knockout, Reporter gene assay, GST-pull down, Sequencing and Single-Strand Conformation Polymorphism (SSCP). 
1 INTRODUÇÃO 
A galectina-3 é uma proteína da crescente família de lectinas animais com afinidade por $\beta$-galactosídeos ${ }^{(1)}$. A expressão de galectina-3 foi associada ao câncer em vários tecidos (2). Na tiróide, uma alta expressão desta proteína é observada em neoplasias foliculares, sugerindo o uso da imunodetecção de galectina-3 como um potencial marcador de malignidade em neoplasias de tiróide ${ }^{(3-5)}$.

A punção de agulha fina (PAF) é um procedimento bem estabelecido utilizado no diagnóstico de nódulos tiroidianos. Entretanto, a distinção diagnóstica entre os tumores foliculares benignos e malignos (adenoma folicular vs carcinoma folicular) somente com base em características citológicas é extremamente difícil ${ }^{(6)}$. Mesmo após a avaliação histológica criteriosa de invasão vascular e capsular nem sempre é possível diferenciar o carcinoma do adenoma folicular ${ }^{(6)}$. Como conseqüência, a maioria dos pacientes com estas lesões são encaminhados para a cirurgia. Por esta razão, a expressão de galectina-3 foi amplamente investigada para fins de diagnóstico, uma vez que vários autores mostraram que galectina-3 apresenta uma alta expressão no câncer de tiróide e uma expressão muito baixa ou ausente em tumor benigno e tecido normal ${ }^{(3-5,7)}$. Por outro lado, a expressão de galectina-3 também foi observada, com uma freqüência menor, em tumores benignos ${ }^{(8-11)}$ e em casos considerados suspeitos de malignidade pela análise histológica ${ }^{(3,8)}$, sugerindo um envolvimento de galectina-3 na progressão tumoral.

Apesar da expressão de galectina-3 ter sido amplamente investigada no câncer de tiróide, muito pouco é conhecido sobre o papel desta proteína na fisiologia e na tumorigênese da tiróide.

\subsection{O CÂNCER DE TIRÓIDE}

O câncer de tiróide representa a malignidade endócrina mais comum. Nódulos tiroidianos palpáveis estão presentes em $4 \%$ a $5 \%$ da população adulta, no entanto, apenas uma pequena fração destas lesões representa câncer ${ }^{(12)}$. A tiróide é constituída de dois tipos distintos de células produtoras de hormônio, as células foliculares de origem epitelial, que são responsáveis pela produção dos hormônios tiroidianos triiodotironina $\left(\mathrm{T}_{3}\right)$ e tiroxina $\left(\mathrm{T}_{4}\right)$; e as células $\mathrm{C}$ originárias da crista neural, que são responsáveis pela produção do hormônio calcitonina ${ }^{(13)}$. Os carcinomas tiroidianos são classificados com base em parâmetros clínicos e histológicos e incluem os subtipos: folicular, papilífero e indiferenciado (anaplásico) que 
são originados da célula folicular e o carcinoma medular que é originado da célula $\mathrm{C}^{(14)}$. O tipo mais prevalente de câncer da tiróide é o carcinoma papilífero e representam 85 a $90 \%$ dos $\operatorname{casos}^{(13)}$.

A via de sinalização MAPK (do inglês: Mitogen-Activated Protein Kinase) é a via mais estudada na tumorigênese da tiróide ${ }^{(15)}$ (Figura 1). Alterações genéticas envolvendo os genes que codificam o receptor tirosina quinase RET, e os dois efetores intracelulares RAS e BRAF são freqüentes no carcinoma papilífero. O receptor RET não é expresso na célula folicular de tiróide, no entanto, ele pode ser ativado pelo rearranjo cromossômico conhecido como RET/PTC, que é resultado da fusão do domínio tirosina quinase do receptor RET com a seqüência $\mathrm{N}$-terminal codificada por genes heterólogos. Este rearranjo promove uma alta expressão do oncogene $R E T / P T C$ na célula folicular e a ativação constitutiva do domínio tirosina quinase do receptor de RET que sinaliza através da via MAPK ${ }^{(16)}$

As mutações ativadoras no gene $B R A F$ e $R A S$ e o rearranjo RET/PTC são observados em mais de $70 \%$ dos casos de carcinoma papilífero e raramente ocorre sobreposição no mesmo tumor ${ }^{(17,18)}$, sugerindo que a ativação desta via é um evento essencial no desenvolvimento do câncer e a alteração de um único efetor desta via é suficiente para a transformação celular ${ }^{(19-21)}$.

Embora $R E T / P T C, R A S$ e $B R A F$ sinalizem por uma via comum (Figura 1), estas alterações genéticas foram associadas a subtipos específicos de carcinoma papilífero, os quais apresentam algumas particularidades quanto a características fenotípicas e perfil de expressão de genes ${ }^{(15)}$. A mutação ativadora no gene $B R A F$ é encontrada no carcinoma papilífero clássico e de célula alta, sendo altamente prevalentes em casos de câncer esporádico em adultos ${ }^{(19)}$, enquanto que a mutação $R A S$ não é restrita a um subtipo específico de câncer de tiróide, sendo mais prevalente em carcinomas pouco-diferenciado e anaplásico ${ }^{(15,22)}$. Por outro lado, o rearranjo RET/PTC é frequentemente encontrado em carcinomas papilíferos ocultos ou microscópicos ${ }^{(21)}$ e são particularmente prevalentes em casos pediátricos e de pacientes expostos à radiação ionizante ${ }^{(23-25)}$.

Além destas causas genéticas já bem estabelecidas, a ativação de PI3K (do inglês: Phosphatidil-Inositol 3-Kinase) e a sinalização WNT/ $\beta$-catenina também são eventos observados durante a progressão do câncer de tiróide ${ }^{(26-30)}$. Estudos recentes mostram que a ativação constitutiva da via MAPK pelos oncogenes $R E T / P T C$ ou $R A S$, podem convergir para a via PI3K/AKT e WNT/ $\beta$-catenina ${ }^{(27,31)}$. 


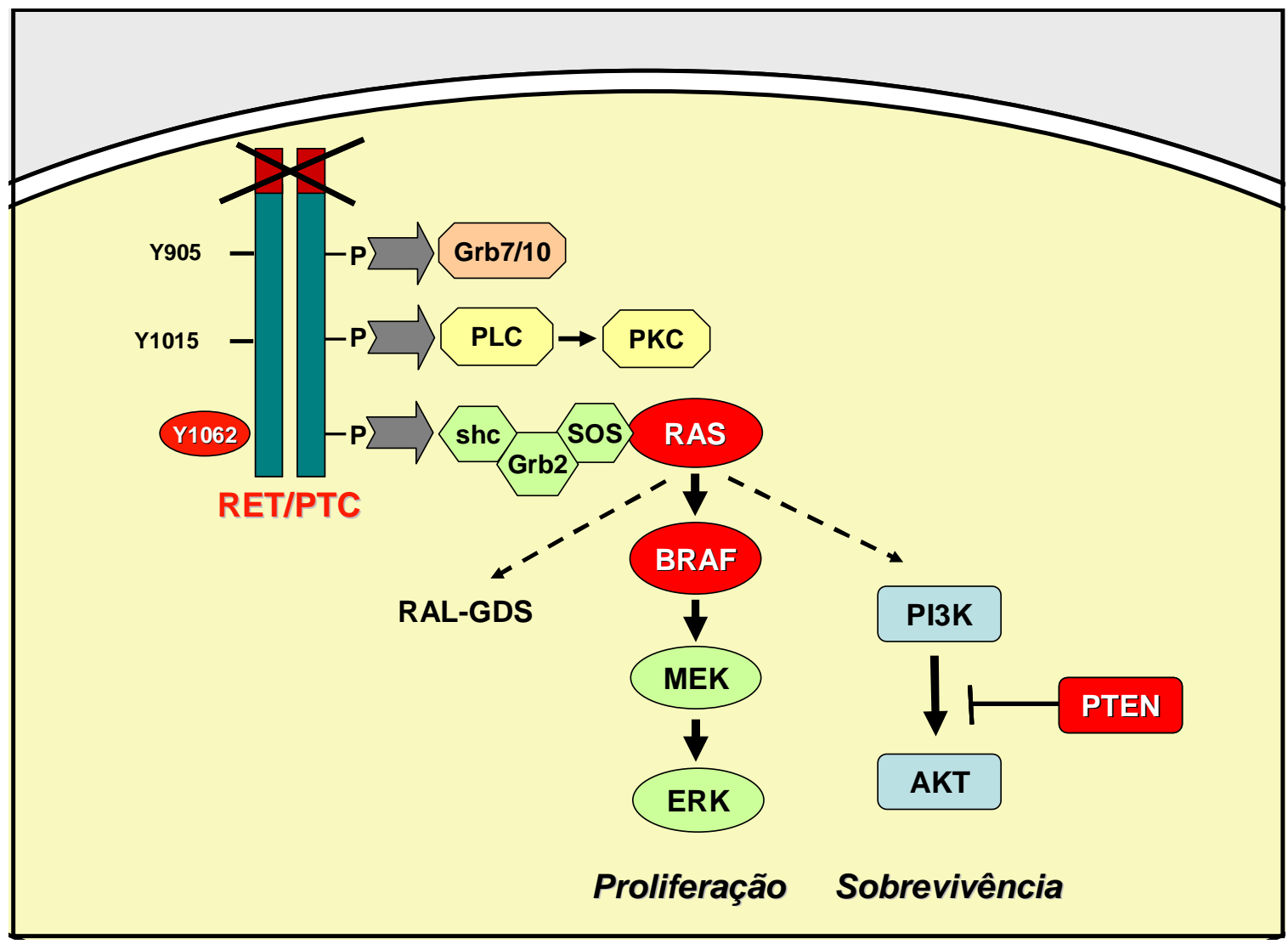

Figura 1 - A via de sinalização MAPK e alterações genéticas comuns no câncer de tiróide. Mutação BRAF, RAS e PTEN (vermelho) e rearranjo RET/PTC (escrito em vermelho) que são comumente observados no câncer de tiróide e a via de sinalização que eles controlam. As mutações mutuamente exclusivas dos genes RET/PTC, RAS ou BRAF fornecem evidências genéticas de que a sinalização MAPK exerce um papel essencial na tumorigênese da tiróide. Além disto, estudos recentes apontam para um importante papel da via PI3K/AKT na tumorigênese da tiróide. Adaptada de Riesco-Eizaguirre ${ }^{(15)}$ (2007).

A proteína AKT, também conhecida como PKB (do inglês: protein kinase B), é uma proteína serina-treonina quinase ativada por PI3K (do inglês: Phosphatidylinositol 3-Kinase) (27). Entre outras vias, AKT pode ativar transdução do sinal de $\beta$-catenina através da regulação negativa da atividade de GSK3 ${ }^{(27)}$.

A $\beta$-catenina é um componente central na via de transdução do sinal WNT e também é um componente integral das junções celulares de adesão (Figura 2) ${ }^{(32)}$. Na ausência da sinalização WNT, a $\beta$-catenina é fosforilada por proteínas serina-treonina quinases, caseína quinase e GSK3 $\beta$ (do inglês: Glycogen Synthase Kinase-3 $\beta$ ). A interação entre estas quinases e a $\beta$-catenina é facilitada pelas proteínas axina e APC (do inglês: Adenomatous Polyposis Coli) que formam um complexo de destruição, que promove a degradação da $\beta$-catenina pelo 
proteassoma (Figura 2A). A ligação da proteína WNT ao seu receptor Frizzled, ativa a cascata de sinalização que inibe a degradação de $\beta$-catenina. A elevação dos níveis de $\beta$-catenina leva ao seu acúmulo no núcleo onde ela forma um complexo com membros da família de fatores de transcrição TCF (do inglês: T-cell Factor Family) e atua como um co-ativador na transcrição de genes alvos (Figura $2 \mathrm{~B}){ }^{(32,33)}$.

A via de sinalização WNT/ $\beta$-catenina exerce um importante papel no desenvolvimento e organogênese de vários tecidos ${ }^{(33,34)}$. Alterações na sinalização WNT/ $\beta$-catenina são responsáveis pelo desenvolvimento de várias doenças, incluindo o câncer e doenças degenerativas ${ }^{(35-37)}$. Mutações no gene que codifica a $\beta$-catenina $(C T N N B 1)$, axina $(A X I N) \mathrm{e}$ APC $(A P C)$, estão entre as alterações genéticas que promovem a ativação constitutiva da via $\mathrm{WNT}^{(32,38,39)}$.

Na tiróide, o papel da cascata de sinalização WNT/ $\beta$-catenina em células normais e no câncer é pouco conhecido. No entanto, estudos recentes mostraram que células foliculares normais expressam os componentes da via de sinalização WNT/ $\beta$-catenina (WNT, Frizzled e Dishevelled) e são capazes de formar o complexo de degradação que consiste de APC, axina e GSK3 ${ }^{(40)}$. No câncer de tiróide, mutação nos genes CTNNB1 e APC foram observadas em carcinomas anaplásicos e pouco diferenciados ${ }^{(28-30)}$. Tanto a mutação no gene CTNNB1 como a expressão elevada de $\beta$-catenina nuclear foram associados a um prognóstico desfavorável e à agressividade do tumor ${ }^{(29,30)}$. Embora estas mutações raramente sejam observadas em carcinomas diferenciados de tiróide, uma alta incidência de carcinoma papilífero é relatada em pacientes com Polipose adenomatosa familiar, uma doença hereditária autossômica dominante causada pela mutação do gene APC na linhagem germinativa ${ }^{(41)}$.

Desta forma, as vias de sinalização PI3K/AKT e WNT/ $\beta$-catenina podem cooperar com a via MAPK durante a tumorigênese e a progressão do câncer de tiróide, controlando várias funções celulares fundamentais, tais como: proliferação, sobrevivência e diferenciação (27, 42-44). 


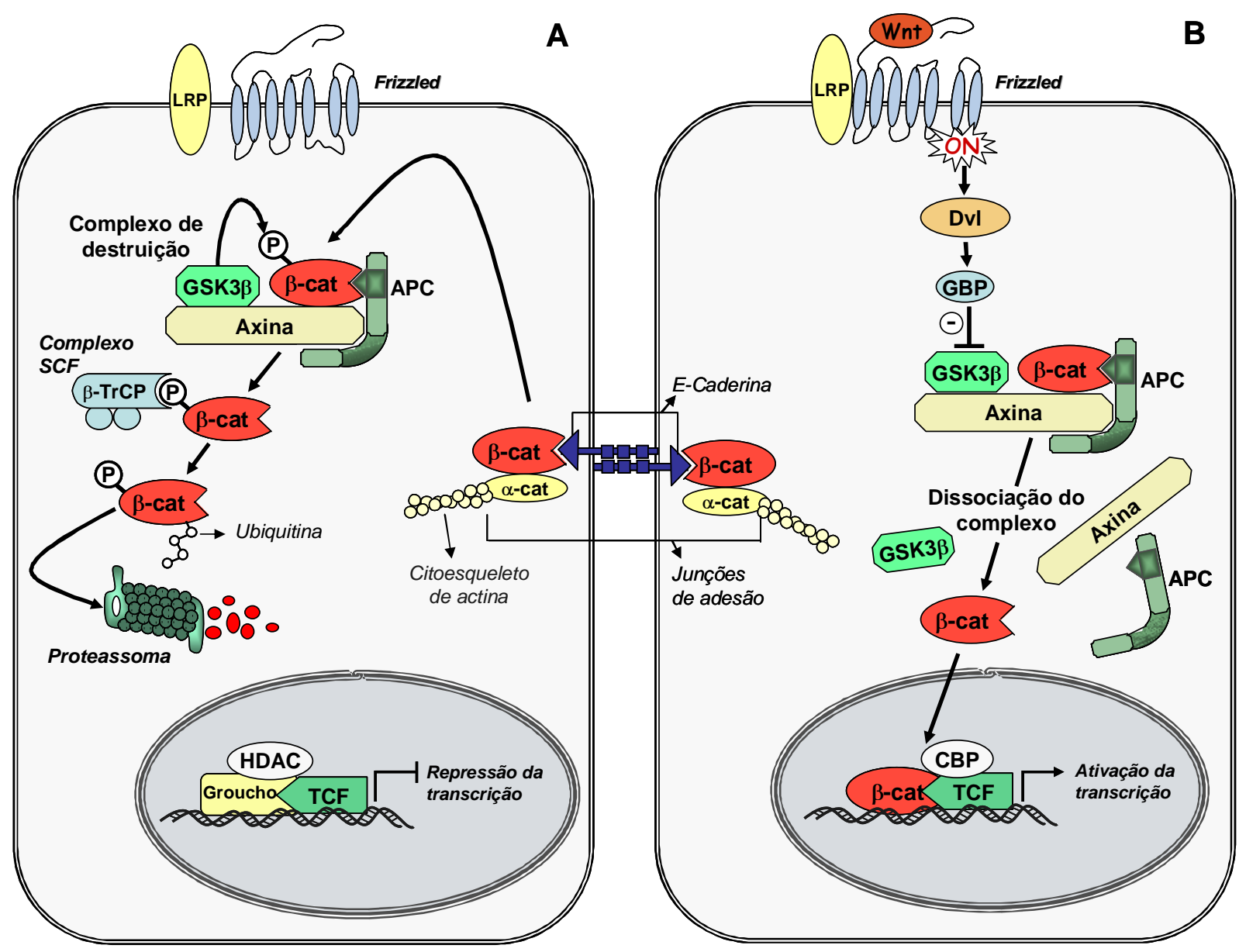

Figura 2 - Via de sinalização WNT/ $\beta$-catenina. A) Na ausência do sinal WNT, os níveis de $\beta$ catenina livre são constantemente controlados por degradação no proteassoma. A $\beta$ catenina livre no citoplasma, a qual está em equilíbrio com a $\beta$-catenina nas junções de adesão, é recrutada para o "complexo de destruição" contendo APC, axina e GSK3ß. A GSK3 $\beta$ fosforila a proteína $\beta$-catenina, que então é reconhecida pelo complexo de ubiquitinação SCF (do inglês: Skp1-Cul1-F-box) contendo a proteína $\beta$-TrCP (do inglês: $\beta$-Transducin Repeat-Containing Protein). Proteínas presentes neste complexo catalisam a adição de uma cadeia de ubiquitinas à $\beta$-catenina e assim a $\beta$-catenina pode ser reconhecida e degradada pelo proteassoma. Na ausência de sinalização de $\beta$-catenina o complexo TCF/Groucho interage com histonas desacetilases (HDAC) e reprime a transcrição de genes alvos. B) Na presença de WNT, seu receptor Frizzled, forma complexo com a proteína LPR e se torna ativado. Isto leva a uma cascata de sinalização intracelular que é ainda pouco compreendida, na qual Dishevelled (DVL) ativa GBP, um inibidor da atividade de GSK3 $\beta$. Consequentemente, $\beta$-catenina não é fosforilada pela GSK3 $\beta$ e não é degradada pelo proteassoma. A $\beta$-catenina livre se acumula no citoplasma e é então translocada para o núcleo, onde ela age convertendo o complexo repressor $\mathrm{TCF} /$ Groucho em um complexo ativador TCF/ $\beta$-catenina que recruta o co-ativador $\mathrm{CPB}$, ativando assim a transcrição de genes responsivos a TCF. Adaptado de Fodde ${ }^{(32)}$ (2001). 
A tiróide adulta caracteriza-se por baixa renovação de suas células foliculares, entretanto, tumores de tiróide são observados em $4 \%$ da população ${ }^{(12)}$, indicando que as estas células mantêm um potencial para proliferar mediante estímulos mitogênicos.

As células normais necessitam da presença de sinais mitogênicos para sair da quiescência $\left(G_{0}\right)$, iniciar a reentrada no ciclo celular e progredir através da fase $G_{1}$, levando à fase S. A decisão da célula de replicar o DNA e se duplicar é influenciada por sinais extracelulares, tais como soro e fatores de crescimento ${ }^{(42,45)}$. Por outro lado, sinais proliferativos também podem ser desencadeados por proto-oncogenes, mesmo na ausência ou na redução de fatores de crescimento, representando a principal forma pela qual células tumorais podem atingir uma proliferação descontrolada ${ }^{(42)}$.

Fatores de progressão, tais como ciclina D1 e ciclina E1, quinases dependentes de ciclina (CDKs), E2F, retinoblastoma $(\mathrm{RB}), \mathrm{p} 16, \mathrm{p} 21$, p27 e p53 regulam a transição de $\mathrm{G}_{1}$ para fase S (Figura 3) ${ }^{(13)}$.

A ciclina D1 é uma proteína de meia vida curta que se acumula no núcleo após estímulo de fatores de crescimento e é essencial para a progressão do ciclo celular na fase $\mathrm{G}_{1}$ (Figura 3$)^{(45)}$. Os fatores de crescimento podem regular a ciclina D1 por pelo menos 4 mecanismos distintos: indução da transcrição, estabilização da proteína, translocação da proteína para o núcleo e união com seus companheiros catalíticos ${ }^{(45)}$. O fator de transcrição c-Myc também exerce um papel central na transição para a fase S. A expressão desta proteína está ausente em células quiescentes, mas é rapidamente induzida por fatores de crescimento (46). A proteína c-Myc induz a transcrição de vários genes envolvidos na transição $\mathrm{G}_{1} / \mathrm{S}$ e promove a ativação de complexos de ciclina D-CDK4 e ciclina E-CDK2 ${ }^{(46)}$.

A maquinaria do ciclo celular controla não apenas a proliferação, mas também a sobrevivência ou a apoptose ${ }^{(46)}$. A produção excessiva de c-Myc, por exemplo, promove ativação de p19, um inibidor da atividade de MDM2 que, por sua vez, está implicado na degradação de p53 pelo proteassoma ${ }^{(46)}$. A ativação de p53 promove a parada do ciclo celular e/ou apoptose através da ativação transcricional da p21, um inibidor da atividade ciclina-CDK (Figura 3$)^{(13)}$. Desta forma, células normais podem frear uma proliferação descontrolada e prevenir a replicação de células com DNA danificado ${ }^{(13)}$.

As células tumorais, ao contrário de células normais, apresentam progressão do ciclo celular acelerada, resistência a sinais inibitórios e insensibilidade a pontos de checagem de 
DNA danificado ${ }^{(42,45)}$, no entanto, os mecanismos pelos quais estas células escapam da morte e promovem uma proliferação descontrolada não são totalmente compreendidos.

No câncer de tiróide, a expressão de moléculas envolvidas no controle do ciclo celular, tais como ciclina D1, c-Myc, p21, p27, está alterada e é correlacionada com o estágio, a agressividade e o aumento de potencial metastático do tumor ${ }^{(13,14,47)}$.

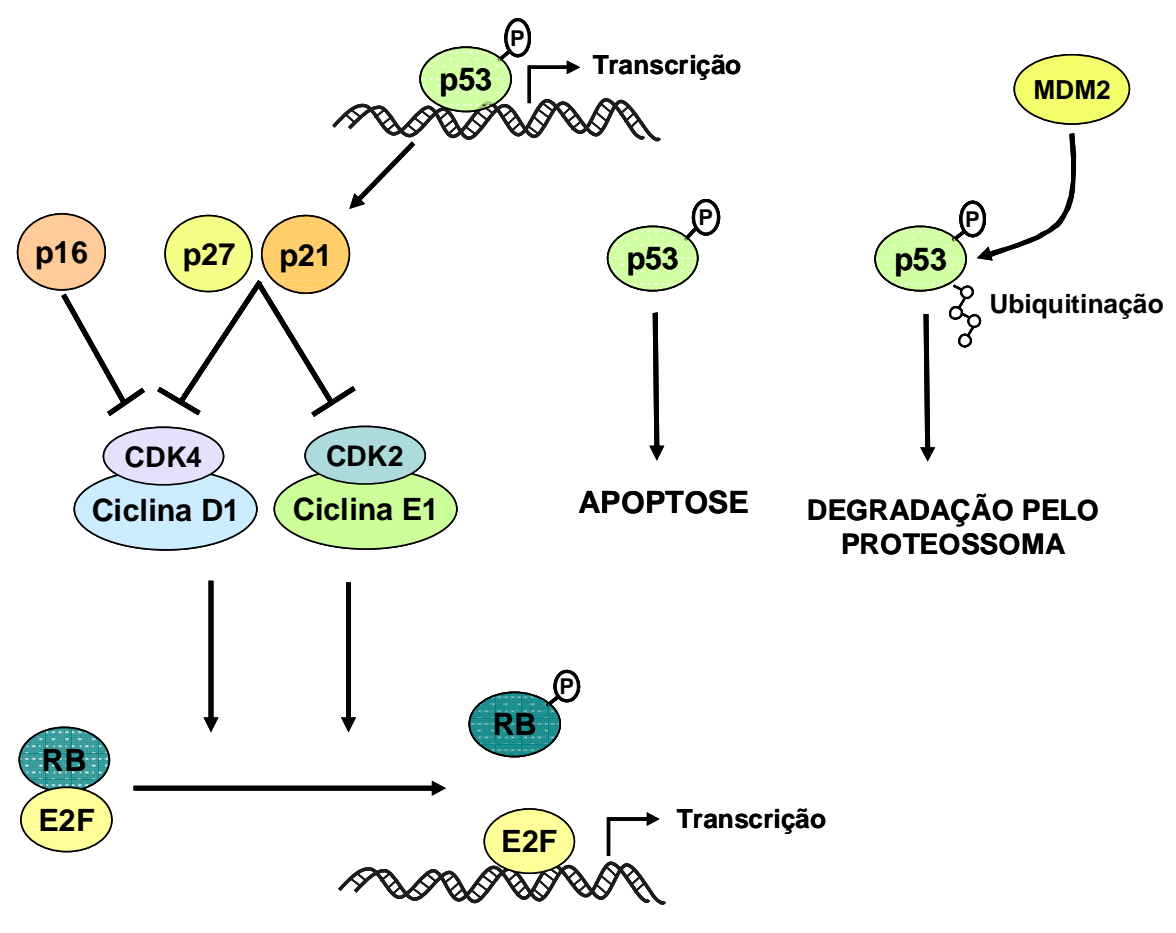

Fase $\mathrm{G}_{1}$

Fase S

Figura 3 - A progressão do ciclo celular através da fase $\mathbf{G}_{\mathbf{1}} / \mathbf{S}$. Ciclina D1 e ciclina E1 cooperam para o controle da transição da fase $G_{1} / S$ através de interações com a proteína retinoblastoma $(\mathrm{RB})$. Ciclina D1 e ciclina $\mathrm{E} 1$ heterodimerizam com quinases ciclinadependentes (CDKs) 4 e 2, respectivamente, para inativar o supressor de tumor RB pela sua fosforilação. A RB não fosforilada atua como um repressor do fator de transcrição $\mathrm{E} 2 \mathrm{~F}$, enquanto que a inativação (fosforilação) de RB permite que a atividade transcricional de E2F prossiga. E2F ativa a transcrição de genes que estão envolvidos na transição da fase $\mathrm{G}_{1}$ para fase $\mathrm{S}$, tais como a DNA polimerase e a timidina quinase. Os inibidores $16 \mathrm{I}^{\mathrm{INK} 4 \mathrm{~A}}, \mathrm{p} 21^{\mathrm{CIP}}$ e $\mathrm{p} 27^{\mathrm{KIP} 1}$, prejudicam a atividade do complexo ciclina-CDK, prevenindo assim a fosforilação de RB. Os inibidores de CDK atuam, por sua vez, como supressores tumorais. O supressor de tumor p53 induz a parada do ciclo celular pela regulação positiva de p21, que inicia a apoptose. Os níveis da proteína p53 na célula são finamente controlados por reguladores negativos, tal como a proteína MDM2. A proteína MDM2 torna a proteína p53 alvo da degradação pelo Proteassoma. Adaptado de Kondo ${ }^{(13)}$ (2006). 
As vias de sinalização MAPK, PI3K/AKT e WNT/ $\beta$-catenina foram associadas ao controle da maquinaria do ciclo celular ${ }^{(42-44,48-50)}$. A via de sinalização PI3K/AKT é a principal via implicada na progressão da fase $G_{1}$ para a fase $S$ do ciclo celular ${ }^{(42)}$. Estudos mostram que a proteína AKT pode regular positivamente a transdução do sinal de $\beta$-catenina através da inativação de GSK3 ${ }^{(27)}$, e assim promover a transcrição de genes alvos da sinalização WNT (Figura 2). Os genes que codificam as proteínas c-Myc (MYC) e ciclina D1 $(C C N D 1)$ são alvos desta via de sinalização ${ }^{(43,44)}$. Outros estudos mostraram que a indução transcricional da ciclina D1 por fatores de crescimento é dependente da via RAS/RAF1/MEK/ERK ${ }^{(48,49)}$. Recentemente, foi demonstrado que a ativação da via MAPK/ERK regula positivamente a transcrição de ciclina $\mathrm{D} 1$, e mais tardiamente a via PI3K promove a estabilização da ciclina D1 ${ }^{(51)}$, sugerindo que a sinalização MAPK e PI3K cooperam para controlar a progressão da fase $G_{1}$ para $S$ do ciclo celular ${ }^{(51)}$. Além disto, a ciclina D1 e o cMyc são proteínas de vida curta, cujos níveis são regulados pela degradação proteolítica dependente de fosforilação pela GSK3 $\beta$ que, por sua vez, tem a atividade inibida pela via PI3K/AKT ${ }^{(42)}$. AKT pode, ainda, fosforilar diretamente os inibidores p21 e p27 e assim modular sua estabilidade, localização e atividade ${ }^{(42)}$.

A ativação das vias de sinalização MAPK e PI3K também foram implicadas na regulação da sobrevivência e proliferação independente de ancoragem de células tumorais ${ }^{(52)}$. A capacidade de sobreviver e proliferar independentemente de ancoragem é uma propriedade necessária para que células tumorais adquiram um fenótipo invasivo. Células epiteliais mostram uma sobrevivência dependente de ancoragem, a qual é mediada por interações com a matriz extracelular e com células vizinhas. A destruição destas interações leva a uma versão especializada de apoptose causada pela perda de adesão a matriz (anokis) ${ }^{(52,53)}$.

A perda da diferenciação celular, fenômeno conhecido como desdiferenciação, é uma característica comum à progressão tumoral. A diferenciação da célula folicular tiroidiana na embriogênese e a manutenção da homeostase durante a fase adulta são reguladas pelos fatores de transcrição TTF-1 (do inglês: Thyroid Transcription Factor 1), PAX-8 (do inglês: Paired box 8) e TTF-2 (também conhecida como forkhead box E1, FOXE1) ${ }^{(54,55)}$. Estes fatores cooperam para regular a transcrição da tireoglobulina, do transportador de sódio e iodo (NIS; do inglês: $\mathrm{Na}^{+} / \mathrm{I}^{-}$Simporter), do receptor de hormônio tireoestimulante (R-TSH) e da tireoperoxidase (TPO), os quais são essenciais para a função tiroidiana ${ }^{(56,57)}$. No câncer de tiróide, o fenótipo indiferenciado está intimamente relacionado à perda da expressão de fatores de transcrição TTF-1 e PAX-8 e de genes por eles regulados (tireoglobulina, TPO, 
NIS e R-TSH) ${ }^{(58)}$. Além disto, a diminuição na expressão destes genes também foi observada em carcinomas papilíferos e foliculares pouco-diferenciados ${ }^{(58)}$.

A ativação constitutiva de efetores ao longo da via MAPK foi associada à desdiferenciação celular na tiróide. A expressão de RET/PTC ou mutação $B R A F$ em células foliculares de rato $\mathrm{PCCl} 3$ inibem a expressão de tireoglobulina, NIS e R-TSH ${ }^{(59-61)}$ e este efeito foi associado à diminuição da expressão do fator de transcrição PAX-8 e/ou inibição da atividade transcricional de TTF-1 e PAX-8 ${ }^{(61,62)}$.

Estudos em C. elegans, Drosofila e camundongos mostram que as proteínas da família WNT são as principais moléculas envolvidas na indução embrionária, geração de polaridade celular e especificação do destino da célula ${ }^{(34)}$. Entretanto, o papel da sinalização WNT na diferenciação da célula tiroidiana em condições fisiológicas ou patológicas é pouco conhecido. A ativação constitutiva da via de sinalização WNT/ $\beta$-catenina, por mutação nos genes $A P C$ e $C T N N B 1$, é frequentemente observadas em tumores pouco-diferenciados e indiferenciados de tiróide, sugerindo que a ativação desta via pode contribuir para a desdiferenciação da célula tumoral ${ }^{(29,30)}$. Além disto, um estudo recente em linhagem celular diferenciada de tiróide de rato FRTL-5 mostrou que a ativação da via WNT/ $\beta$-catenina reprime a transcrição do gene TPO ${ }^{(63)}$.

\subsection{ESTRUTURA E FunÇÃo da GALECTINA-3}

As galectinas são proteínas da crescente família de lectinas animais que se ligam a carboidratos do tipo $\beta$-galactosídeos ${ }^{(1)}$. Os membros desta família também são encontrados em muitas espécies incluindo desde mamíferos, pássaros, peixes, anfíbios, vermes, insetos até espongiários e fungos ${ }^{(64)}$.

As galectinas foram inicialmente identificadas como lectinas que se ligam galactosídeos de extratos de tecido de vertebrados. Em 1994 a família das galectinas foi formalmente definida com base tanto na homologia da seqüência como na sua propriedade de ligação à galactosídeos ${ }^{(1)}$. Atualmente, esta família apresenta 14 membros identificados em mamíferos, todos contendo o domínio de reconhecimento de carboidratos (DRC) de aproximadamente 130 aminoácidos. Baseados no número e organização deste domínio, os membros desta família foram classificados dentro de 3 subtipos: O grupo protótipo (galetina$1,-2,-5,-7,-10,-11,-13$ e -14) que apresenta um único DRC, o grupo tanden repeat 
(galectina-4, -6,-8, -9 e 12) que apresentam dois DRC e o grupo quimera que apresenta um DRC conectado a um incomum domínio N-terminal longo que é rico em aminoácidos glicina e prolina ${ }^{(65,66)}$. A galectina-3 é único membro do grupo quimera que foi identificado em vertebrados $(65,66)$.

A galectina-3 é possivelmente a proteína mais estudada entre os membros da família de galectinas ${ }^{(67)}$. Esta proteína monomérica foi inicialmente identificada como Mac-2, um antígeno de $32 \mathrm{kDa}$ expresso na superfície celular de macrófagos peritoniais de camundongos (68). Desde então, esta proteína foi descrita como proteína que se liga a $\operatorname{IgE}$ (IgE binding protein), CBP35, عBP, RL-29, HL-29, LBP e L-34, até que em 1994 ela foi oficialmente denominada galectina-3 ${ }^{(1)}(67)$.

O gene LGALS3 (do inglês: Lectin, GALactoside-binding, Soluble, 3), que codifica a galectina-3 humana, está localizado no lócus 14q21-22 e transcreve para um mRNA de $11 \mathrm{~kb}$ de 6 éxons e 5 íntrons ${ }^{(69)}$. Este gene apresenta vários candidatos a SNPs anotados, os quais estão depositados nos bancos de dados públicos de Single Nucleotide Polimorphism do NCBI (http://www.ncbi.nlm.nih.gov/entrez/query.fcgi?CMD=search\&DB=snp), mas uma relação entre estes SNPs e variações fenotípicas específicas relevantes à saúde não foi avaliada. A investigação de SNPs tem auxiliado na compreensão de genes que influenciam o risco de desenvolver câncer ${ }^{(70-76)}$. Assim, o fato de galectina-3 ter sido associada ao câncer em vários tecidos faz com que o gene $L G A L S 3$ seja um interessante alvo para identificação de SNPs.

A galectina-3 é encontrada em vários tecidos tanto em condições normais como patológicas ${ }^{(2,67)}$. Embora a expressão de galectina-3 tenha sido observada em uma infinidade de tecidos normais, ela é principalmente descrita em tecidos de origem epitelial e em células do sistema imunológico ${ }^{(67)}$. A expressão de galectina-3 também é observada em uma grande variedade de carcinomas ${ }^{(2)}$.

A galectina-3 é predominantemente observada no citoplasma, mas pode ser transportada para o núcleo ${ }^{(64)}$ ou secretada para o espaço extracelular ${ }^{(77)}$. Estudos recentes mostraram que galectina-3 pode migrar para o núcleo por pelo menos duas vias distintas: difusão passiva ou por transporte ativo dependente da ligação às proteínas que facilitam o transporte através do poro nuclear ${ }^{(78,79)}$.

O papel biológico de galectina-3 não é totalmente compreendido, no entanto, ela tem sido associada a vários processos fisiológicos e patológicos importantes, tais como: progressão e metástase de tumores ${ }^{(80-83)}$, processo inflamatório ${ }^{(84)}$, morfogênese e 
angiogênese ${ }^{(85)}$. Várias funções intracelulares e extracelulares foram associadas a esta proteína ${ }^{(86,87)}$. No compartimento extracelular, a galectina-3 foi associada à adesão celular sugerindo que ela possa desempenhar um papel na embriogênese, angiogênese, endocitose (87). Intracelularmente, a galectina-3 foi associada à proliferação, anti-apoptose e processamento de pré-mRNA ${ }^{(86)}$.

Os mecanismos moleculares pelo qual galectina-3 desempenha uma função na tumorigênese são ainda pouco compreendidos. No câncer de mama, a expressão elevada de galectina-3 foi associada à supressão da apoptose induzida pela perda de ancoragem ${ }^{(88)}$, óxido nítrico ${ }^{(89)}$ ou drogas anti-câncer como a cisplatinum ${ }^{(90)}$ e Genistein ${ }^{(91)}$. Diferentes iniciativas mostraram que a galectina-3 pode suprimir a apoptose por, pelo menos, 3 mecanismos distintos: inibição da via que envolve a proteína supressora da apoptose Bcl-2 ${ }^{(92)}$, ativação de proteases cisteínas como a caspase- ${ }^{(90)}$ ou modulação da expressão de genes e da atividade de reguladores do ciclo celular tais como ciclina D1, ciclina E, p21 e p27 ${ }^{(88,93)}$. Um domínio funcional BH1 (NWGR), o qual é altamente conservado entre os membros da família Bcl-2, foi identificado na galectina-3 e a integridade deste domínio parece ser essencial para sua atividade anti-apoptótica e na habilidade para modular a expressão de reguladores do ciclo celular $^{(88,90,92)}$. Por outro lado, Yoshii (2002) mostrou que a fosforilação de galectina-3 na serina 6 (S6) é necessária para a sua função na supressão da apoptose, induzida por perda de ancoragem ou tratamento com drogas anti-tumorais e na regulação da expressão e atividade de reguladores do ciclo celular ${ }^{(93)}$.

Interessantemente, a galectina-3 foi associada a duas importantes vias envolvidas no controle do ciclo celular e na regulação transcricional da ciclina D $1^{(94-97)}$. Estudos em linhagens de carcinoma mamário e fibroblastos mostraram que a galectina-3 pode se associar à RAS e modular sua atividade na célula ${ }^{(96,97)}$. Entretanto, embora RAS seja um importante efetor da via de sinalização MAPK, a qual é frequentemente alterada no câncer de tiróide, um envolvimento de galectina-3 na transdução do sinal de RAS e na via MAPK na tiróide nunca foi investigada. Além disto, outro estudo mostrou que galectina-3 pode se ligar à $\beta$-catenina e ativar a transcrição de genes alvos da via de sinalização na linhagem de câncer de mama BT549 ${ }^{(95)}$. Por outro lado, o papel da via de sinalização WNT/ $\beta$-catenina na tumorigênese da tiróide ainda é pouco compreendido e as implicações de galectina-3 nesta via em células tiroidianas nunca foram investigadas.

Poucos estudos têm contribuído para elucidar o mecanismo molecular pelo qual galectina-3 desempenha um papel na tumorigênese da tiróide. Estudos in vitro na linhagem de 
carcinoma papilífero de tiróide e na linhagem embrionária de tiróide humana TAD2 mostram que a expressão elevada de galectina-3 confere a célula a capacidade de proliferar independentemente de soro, ancoragem ou contato com outras células ${ }^{(98,99)}$. Além disso, outro estudo mostrou que a expressão de galectina-3 é positivamente regulada pela transformação maligna da linhagem celular de tiróide de rato FTRL5 como o oncogene RAS e que galectina-3 pode se ligar ao homeodomínio do fator de transcrição TTF-1 e regular positivamente a sua função no promotor de $T g^{(100)}$.

Desta forma, a expressão de galectina-3 foi associada a vários processos biológicos que estão comumente alterados no câncer, entretanto, a função específica da galectina-3 na fisiologia e patologia da tiróide não é conhecida. 
6 CONCLUSÃo 
Identificamos 4 SNPs no gene LGALS3 (P64H, T98P, R183K, Q201H) de tumores benignos e malignos de tiróide. A análise detalhada do SNP T98P mostra que não existe associação entre os genótipos do SNP T98P do LGALS3 e o fenótipo de tumor benigno ou maligno da tiróide.

A expressão de galectina-3 é regulada positivamente pela a indução da expressão do oncogene RET/PTC na linhagem folicular de tiróide de rato $\mathrm{PCCl}$, sugerindo um envolvimento de galectina-3 em eventos iniciais da tumorigênese da tiróide.

$\mathrm{Na}$ linhagem de carcinoma papilífero de tiróide TPC-1, a galectina-3 favorece a sobrevivência da célula tumoral e a progressão do ciclo celular, aumentando a expressão gênica e proteica de c-Myc e reduzindo a expressão de p21 e da caspase-3. A proteína galectina-3 se liga à $\beta$-catenina e regula, positivamente, a expressão dos genes MYC e CCND1. Além disto, a galectina-3 favorece a ativação tanto a via de sinalização AKT como da via ERK, sugerindo que este poderia ser um dos mecanismos pelo qual galectina-3 regula a estabilidade e atividade de importantes reguladores do ciclo celular (por exemplo: c-Myc e p21) na célula tumoral de tiróide.

A indução da expressão de galectina-3, na célula folicular da tiróide, aumenta a expressão de $M Y C$ e $C C N D 1$, mas não confere a célula um aumento na progressão do ciclo celular, sugerindo que o efeito de galectina-3 na proliferação e sobrevivência da célula tumoral é um evento secundário ao desenvolvimento do tumor e é dependente de alterações moleculares prévias.

A galectina-3 não é essencial para o desenvolvimento normal da glândula tiróide durante a embriogênese. Por outro lado, a ausência de galectina-3 modifica a histomorfologia e o padrão de expressão da tiroglobulina na tiróide de camundongos knockout para a galectina-3 tratados com drogas bociogênicas. Na célula folicular tiroidiana, a galectina-3 aumenta a expressão e a transcrição do gene $T g$, mas este efeito é prejudicado pela ativação constitutiva da via de sinalização WNT/ $\beta$-catenina. O efeito da galectina-3 na regulação da transcrição de tiroglobulina é um efeito indireto e dependente da presença de TTF-1, uma vez que a galectina-3 não forma complexo com fatores de transcrição tiroidianos (TTF-1 ou PAX8) e não exerce efeito no promotor de $T g$ na ausência destes fatores. 
REFERÊNCIAS 


\section{REFERÊNCIAS}

1. Barondes SH, Castronovo V, Cooper DN, Cummings RD, Drickamer K, Feizi T, et al. Galectins: a family of animal beta-galactoside-binding lectins. Cell. 1994;76(4):597-8.

2. Danguy A, Camby I, Kiss R. Galectins and cancer. Biochim Biophys Acta. 2002;1572(2-3):285-93.

3. Bartolazzi A, Gasbarri A, Papotti M, Bussolati G, Lucante T, Khan A, et al. Application of an immunodiagnostic method for improving preoperative diagnosis of nodular thyroid lesions. Lancet. 2001;357(9269):1644-50.

4. Inohara H, Honjo Y, Yoshii T, Akahani S, Yoshida J, Hattori K, et al. Expression of galectin-3 in fine-needle aspirates as a diagnostic marker differentiating benign from malignant thyroid neoplasms. Cancer. 1999;85(11):2475-84.

5. Saggiorato E, Aversa S, Deandreis D, Arecco F, Mussa A, Puligheddu B, et al. Galectin-3: presurgical marker of thyroid follicular epithelial cell-derived carcinomas. J Endocrinol Invest. 2004;27(4):311-7.

6. Sherman SI. Thyroid carcinoma. Lancet. 2003;361(9356):501-11.

7. Xu XC, el-Naggar AK, Lotan R. Differential expression of galectin-1 and galectin-3 in thyroid tumors. Potential diagnostic implications. Am J Pathol. 1995;147(3):815-22.

8. Coli A, Bigotti G, Zucchetti F, Negro F, Massi G. Galectin-3, a marker of welldifferentiated thyroid carcinoma, is expressed in thyroid nodules with cytological atypia. Histopathology. 2002;40(1):80-7.

9. Cvejic D, Savin S, Paunovic I, Tatic S, Havelka M, Sinadinovic J. Immunohistochemical localization of galectin-3 in malignant and benign human thyroid tissue. Anticancer Res. 1998;18(4A):2637-41.

10. Martins L, Matsuo SE, Ebina KN, Kulcsar MA, Friguglietti CU, Kimura ET. Galectin3 messenger ribonucleic acid and protein are expressed in benign thyroid tumors. $\mathrm{J}$ Clin Endocrinol Metab. 2002;87(10):4806-10.

11. Bernet VJ, Anderson J, Vaishnav Y, Solomon B, Saji M, Burman KD, et al. Overexpression of galectin-3 mRNA in papillary thyroid cancer. In: In 12th International Thyroid Congress; 2000; Kyoto: Endocrine journal; 2000. p. 205.

12. Rosai J, Carcangiu ML, DeLellis RA. Tumors of the thyroid gland. Third series, fascicle 5 ed. Washington, DC: Armed Forces Institute of Pathology; 1992. 
13. Kondo T, Ezzat S, Asa SL. Pathogenetic mechanisms in thyroid follicular-cell neoplasia. Nat Rev Cancer. 2006;6(4):292-306.

14. Segev DL, Umbricht C, Zeiger MA. Molecular pathogenesis of thyroid cancer. Surg Oncol. 2003;12(2):69-90.

15. Riesco-Eizaguirre G, Santisteban P. New insights in thyroid follicular cell biology and its impact in thyroid cancer therapy. Endocr Relat Cancer. 2007;14(4):957-977.

16. Ciampi R, Nikiforov YE. RET/PTC rearrangements and BRAF mutations in thyroid tumorigenesis. Endocrinology. 2007;148(3):936-41.

17. Fagin JA. Challenging dogma in thyroid cancer molecular genetics--role of RET/PTC and BRAF in tumor initiation. J Clin Endocrinol Metab. 2004;89(9):4264-6.

18. Kimura ET, Nikiforova MN, Zhu Z, Knauf JA, Nikiforov YE, Fagin JA. High prevalence of BRAF mutations in thyroid cancer: genetic evidence for constitutive activation of the RET/PTC-RAS-BRAF signaling pathway in papillary thyroid carcinoma. Cancer Res. 2003;63(7):1454-7.

19. Nikiforova MN, Kimura ET, Gandhi M, Biddinger PW, Knauf JA, Basolo F, et al. BRAF mutations in thyroid tumors are restricted to papillary carcinomas and anaplastic or poorly differentiated carcinomas arising from papillary carcinomas. $\mathbf{J}$ Clin Endocrinol Metab. 2003;88(11):5399-404.

20. Namba H, Rubin SA, Fagin JA. Point mutations of ras oncogenes are an early event in thyroid tumorigenesis. Mol Endocrinol. 1990;4(10):1474-9.

21. Viglietto G, Chiappetta G, Martinez-Tello FJ, Fukunaga FH, Tallini G, Rigopoulou D, et al. RET/PTC oncogene activation is an early event in thyroid carcinogenesis. Oncogene. 1995;11(6):1207-10.

22. Garcia-Rostan G, Zhao H, Camp RL, Pollan M, Herrero A, Pardo J, et al. ras mutations are associated with aggressive tumor phenotypes and poor prognosis in thyroid cancer. J Clin Oncol. 2003;21(17):3226-35.

23. Bounacer A, Wicker R, Schlumberger M, Sarasin A, Suarez HG. Oncogenic rearrangements of the ret proto-oncogene in thyroid tumors induced after exposure to ionizing radiation. Biochimie. 1997;79(9-10):619-23.

24. Nikiforov YE, Rowland JM, Bove KE, Monforte-Munoz H, Fagin JA. Distinct pattern of ret oncogene rearrangements in morphological variants of radiation-induced and sporadic thyroid papillary carcinomas in children. Cancer Res. 1997;57(9):1690-4.

25. Klugbauer S, Lengfelder E, Demidchik EP, Rabes HM. High prevalence of RET rearrangement in thyroid tumors of children from Belarus after the Chernobyl reactor accident. Oncogene. 1995;11(12):2459-67. 
26. Vasko V, Saji M, Hardy E, Kruhlak M, Larin A, Savchenko V, et al. Akt activation and localisation correlate with tumour invasion and oncogene expression in thyroid cancer. J Med Genet. 2004;41(3):161-70.

27. Shinohara M, Chung YJ, Saji M, Ringel MD. AKT in thyroid tumorigenesis and progression. Endocrinology. 2007;148(3):942-7.

28. Zeki K, Spambalg D, Sharifi N, Gonsky R, Fagin JA. Mutations of the adenomatous polyposis coli gene in sporadic thyroid neoplasms. J Clin Endocrinol Metab. 1994;79(5):1317-21.

29. Garcia-Rostan G, Tallini G, Herrero A, D'Aquila TG, Carcangiu ML, Rimm DL. Frequent mutation and nuclear localization of beta-catenin in anaplastic thyroid carcinoma. Cancer Res. 1999;59(8):1811-5.

30. Garcia-Rostan G, Camp RL, Herrero A, Carcangiu ML, Rimm DL, Tallini G. Betacatenin dysregulation in thyroid neoplasms: down-regulation, aberrant nuclear expression, and CTNNB1 exon 3 mutations are markers for aggressive tumor phenotypes and poor prognosis. Am J Pathol. 2001;158(3):987-96.

31. Abbosh PH, Nephew KP. Multiple signaling pathways converge on beta-catenin in thyroid cancer. Thyroid. 2005;15(6):551-61.

32. Fodde R, Smits R, Clevers H. APC, signal transduction and genetic instability in colorectal cancer. Nat Rev Cancer. 2001;1(1):55-67.

33. Nusse R. Wnt signaling in disease and in development. Cell Res 2005;15(1):28-32.

34. Cadigan KM, Nusse R. Wnt signaling: a common theme in animal development. Genes Dev. 1997;11(24):3286-305.

35. De Ferrari GV, Moon RT. The ups and downs of Wnt signaling in prevalent neurological disorders. Oncogene. 2006;25(57):7545-53.

36. Oshima H, Oshima M, Kobayashi M, Tsutsumi M, Taketo MM. Morphological and molecular processes of polyp formation in Apc(delta716) knockout mice. Cancer Res. 1997;57(9):1644-9.

37. Powell SM, Zilz N, Beazer-Barclay Y, Bryan TM, Hamilton SR, Thibodeau SN, et al. APC mutations occur early during colorectal tumorigenesis. Nature. 1992;359(6392):235-7.

38. Webster MT, Rozycka M, Sara E, Davis E, Smalley M, Young N, et al. Sequence variants of the axin gene in breast, colon, and other cancers: an analysis of mutations that interfere with GSK3 binding. Genes Chromosomes Cancer 2000;28(4):443-53. 
39. Polakis P. The oncogenic activation of beta-catenin. Curr Opin Genet Dev. 1999;9(1):15-21.

40. Helmbrecht $\mathrm{K}$, Kispert A, von Wasielewski R, Brabant G. Identification of a Wnt/beta-catenin signaling pathway in human thyroid cells. Endocrinology. 2001;142(12):5261-6.

41. Lee S, Hong SW, Shin SJ, Kim YM, Rhee Y, Jeon BI, et al. Papillary thyroid carcinoma associated with familial adenomatous polyposis: molecular analysis of pathogenesis in a family and review of the literature. Endocr J. 2004;51(3):317-23.

42. Liang J, Slingerland JM. Multiple roles of the PI3K/PKB (Akt) pathway in cell cycle progression. Cell Cycle. 2003;2(4):339-45.

43. Tetsu O, McCormick F. Beta-catenin regulates expression of cyclin D1 in colon carcinoma cells. Nature. 1999;398(6726):422-6.

44. He TC, Sparks AB, Rago C, Hermeking H, Zawel L, da Costa LT, et al. Identification of c-MYC as a target of the APC pathway. Science. 1998;281(5382):1509-12.

45. Blagosklonny MV, Pardee AB. The restriction point of the cell cycle. Cell Cycle. 2002;1(2):103-10.

46. Matsumura I, Tanaka H, Kanakura Y. E2F1 and c-Myc in cell growth and death. Cell Cycle. 2003;2(4):333-8.

47. Wang S, Lloyd RV, Hutzler MJ, Safran MS, Patwardhan NA, Khan A. The role of cell cycle regulatory protein, cyclin D1, in the progression of thyroid cancer. Mod Pathol. 2000;13(8):882-7.

48. Winston JT, Coats SR, Wang YZ, Pledger WJ. Regulation of the cell cycle machinery by oncogenic ras. Oncogene. 1996;12(1):127-34.

49. Filmus J, Robles AI, Shi W, Wong MJ, Colombo LL, Conti CJ. Induction of cyclin D1 overexpression by activated ras. Oncogene. 1994;9(12):3627-33.

50. Jones SM, Kazlauskas A. Growth factor-dependent signaling and cell cycle progression. FEBS Lett. 2001;490(3):110-6.

51. Jones SM, Kazlauskas A. Growth-factor-dependent mitogenesis requires two distinct phases of signalling. Nat Cell Biol. 2001;3(2):165-72.

52. Wang LH. Molecular signaling regulating anchorage-independent growth of cancer cells. Mt Sinai J Med. 2004;71(6):361-7. 
53. Frisch SM. E1a induces the expression of epithelial characteristics. J Cell Biol. 1994;127(4):1085-96.

54. Di Lauro R, Damante G, De Felice M, Arnone MI, Sato K, Lonigro R, et al. Molecular events in the differentiation of the thyroid gland. J Endocrinol Invest. 1995;18(2):1179.

55. Missero C, Cobellis G, De Felice M, Di Lauro R. Molecular events involved in differentiation of thyroid follicular cells. Mol Cell Endocrinol. 1998;140(1-2):37-43.

56. Di Palma T, Nitsch R, Mascia A, Nitsch L, Di Lauro R, Zannini M. The paired domain-containing factor Pax8 and the homeodomain-containing factor TTF-1 directly interact and synergistically activate transcription. J Biol Chem. 2003;278(5):3395-402.

57. Di Lauro R. Molecular abnormalities of organogenesis and differentiation of the thyroid gland. Ann Endocrinol. (Paris) 2003;64(1):53.

58. Ros P, Rossi DL, Acebron A, Santisteban P. Thyroid-specific gene expression in the multi-step process of thyroid carcinogenesis. Biochimie. 1999;81(4):389-96.

59. Wang J, Knauf JA, Basu S, Puxeddu E, Kuroda H, Santoro M, et al. Conditional expression of RET/PTC induces a weak oncogenic drive in thyroid PCCL3 cells and inhibits thyrotropin action at multiple levels. Mol Endocrinol. 2003;17(7):1425-36.

60. Knauf JA, Kuroda H, Basu S, Fagin JA. RET/PTC-induced dedifferentiation of thyroid cells is mediated through Y1062 signaling through SHC-RAS-MAP kinase. Oncogene. 2003;22(28):4406-12.

61. Mitsutake N, Knauf JA, Mitsutake S, Mesa C, Jr., Zhang L, Fagin JA. Conditional BRAFV600E expression induces DNA synthesis, apoptosis, dedifferentiation, and chromosomal instability in thyroid PCCL3 cells. Cancer Res. 2005;65(6):2465-73.

62. Missero C, Pirro MT, Di Lauro R. Multiple ras downstream pathways mediate functional repression of the homeobox gene product TTF-1. Mol Cell Biol. 2000;20(8):2783-93.

63. Kim WB, Lewis CJ, McCall KD, Malgor R, Kohn AD, Moon RT, et al. Overexpression of Wnt-1 in thyrocytes enhances cellular growth but suppresses transcription of the thyroperoxidase gene via different signaling mechanisms. J Endocrinol. 2007;193(1):93-106.

64. Cooper DN, Barondes SH. God must love galectins; he made so many of them. Glycobiology. 1999;9(10):979-84.

65. Cooper DN. Galectinomics: finding themes in complexity. Biochim Biophys Acta. 2002;1572(2-3):209-31. 
66. Barondes SH, Cooper DN, Gitt MA, Leffler H. Galectins. Structure and function of a large family of animal lectins. J Biol Chem. 1994;269(33):20807-10.

67. Dumic J, Dabelic S, Flogel M. Galectin-3: an open-ended story. Biochim Biophys Acta. 2006;1760(4):616-35.

68. Ho MK, Springer TA. Mac-2, a novel 32,000 Mr mouse macrophage subpopulationspecific antigen defined by monoclonal antibodies. J Immunol. 1982;128(3):1221-8.

69. Kadrofske MM, Openo KP, Wang JL. The human LGALS3 (galectin-3) gene: determination of the gene structure and functional characterization of the promoter. Arch Biochem Biophys. 1998;349(1):7-20.

70. Erichsen HC, Chanock SJ. SNPs in cancer research and treatment. Br J Cancer. 2004;90(4):747-51.

71. Kaklamani VG, Hou N, Bian Y, Reich J, Offit K, Michel LS, et al. TGFBR1*6A and cancer risk: a meta-analysis of seven case-control studies. $\mathrm{J}$ Clin Oncol. 2003;21(17):3236-43.

72. Stephens LA, Powell NG, Grubb J, Jeremiah SJ, Bethel JA, Demidchik EP, et al. Investigation of loss of heterozygosity and SNP frequencies in the RET gene in papillary thyroid carcinoma. Thyroid. 2005;15(2):100-4.

73. Baumgartner-Parzer SM, Lang R, Wagner L, Heinze G, Niederle B, Kaserer K, et al. Polymorphisms in exon 13 and intron 14 of the RET protooncogene: genetic modifiers of medullary thyroid carcinoma? J Clin Endocrinol Metab. 2005;90(11):6232-6.

74. Granja F, Morari J, Morari EC, Correa LA, Assumpcao LV, Ward LS. Proline homozygosity in codon 72 of p53 is a factor of susceptibility for thyroid cancer. Cancer Lett. 2004;210(2):151-7.

75. Basolo F, Giannini R, Faviana P, Fontanini G, Patricelli Malizia A, Ugolini C, et al. Thyroid papillary carcinoma: preliminary evidence for a germ-line single nucleotide polymorphism in the Fas gene. J Endocrinol. 2004;182(3):479-84.

76. Matakidou A, Hamel N, Popat S, Henderson K, Kantemiroff T, Harmer C, et al. Risk of non-medullary thyroid cancer influenced by polymorphic variation in the thyroglobulin gene. Carcinogenesis. 2004;25(3):369-73.

77. Hughes RC. Secretion of the galectin family of mammalian carbohydrate-binding proteins. Biochim Biophys Acta 1999;1473(1):172-85.

78. Nakahara S, Hogan V, Inohara H, Raz A. Importin-mediated nuclear translocation of galectin-3. J Biol Chem. 2006;281(51):39649-59. 
79. Nakahara S, Oka N, Wang Y, Hogan V, Inohara H, Raz A. Characterization of the nuclear import pathways of galectin-3. Cancer Res. 2006;66(20):9995-10006.

80. van den Brule FA, Waltregny D, Liu FT, Castronovo V. Alteration of the cytoplasmic/nuclear expression pattern of galectin-3 correlates with prostate carcinoma progression. Int J Cancer. 2000;89(4):361-7.

81. Castronovo V, Van Den Brule FA, Jackers P, Clausse N, Liu FT, Gillet C, et al. Decreased expression of galectin-3 is associated with progression of human breast cancer. J Pathol. 1996;179(1):43-8.

82. Lee JW, Song SY, Choi JJ, Choi CH, Kim TJ, Kim J, et al. Decreased galectin-3 expression during the progression of cervical neoplasia. J Cancer Res Clin Oncol. 2006;132(4):241-7.

83. Bresalier RS, Mazurek N, Sternberg LR, Byrd JC, Yunker CK, Nangia-Makker P, et al. Metastasis of human colon cancer is altered by modifying expression of the betagalactoside-binding protein galectin 3. Gastroenterology. 1998;115(2):287-96.

84. Almkvist J, Karlsson A. Galectins as inflammatory mediators. Glycoconj J. 2004;19(7-9):575-81.

85. Nangia-Makker P, Baccarini S, Raz A. Carbohydrate-recognition and angiogenesis. Cancer Metastasis Rev. 2000;19(1-2):51-7.

86. Liu FT, Patterson RJ, Wang JL. Intracellular functions of galectins. Biochim Biophys Acta. 2002;1572(2-3):263-73.

87. Ochieng J, Furtak V, Lukyanov P. Extracellular functions of galectin-3. Glycoconj J. 2004;19(7-9):527-35.

88. Kim HR, Lin HM, Biliran H, Raz A. Cell cycle arrest and inhibition of anoikis by galectin-3 in human breast epithelial cells. Cancer Res. 1999;59(16):4148-54.

89. Moon BK, Lee YJ, Battle P, Jessup JM, Raz A, Kim HR. Galectin-3 protects human breast carcinoma cells against nitric oxide-induced apoptosis: implication of galectin-3 function during metastasis. Am J Pathol. 2001;159(3):1055-60.

90. Akahani S, Nangia-Makker P, Inohara H, Kim HR, Raz A. Galectin-3: a novel antiapoptotic molecule with a functional BH1 (NWGR) domain of Bcl-2 family. Cancer Res. 1997;57(23):5272-6.

91. Lin HM, Pestell RG, Raz A, Kim HR. Galectin-3 enhances cyclin D(1) promoter activity through SP1 and a cAMP-responsive element in human breast epithelial cells. Oncogene. 2002;21(52):8001-10. 
92. Yang RY, Hsu DK, Liu FT. Expression of galectin-3 modulates T-cell growth and apoptosis. Proc Natl Acad Sci U S A. 1996;93(13):6737-42.

93. Yoshii T, Fukumori T, Honjo Y, Inohara H, Kim HR, Raz A. Galectin-3 phosphorylation is required for its anti-apoptotic function and cell cycle arrest. J Biol Chem. 2002;277(9):6852-7.

94. Shimura T, Takenaka Y, Fukumori T, Tsutsumi S, Okada K, Hogan V, et al. Implication of galectin-3 in Wnt signaling. Cancer Res. 2005;65(9):3535-7.

95. Shimura T, Takenaka Y, Tsutsumi S, Hogan V, Kikuchi A, Raz A. Galectin-3, a novel binding partner of beta-catenin. Cancer Res. 2004;64(18):6363-7.

96. Elad-Sfadia G, Haklai R, Balan E, Kloog Y. Galectin-3 augments K-Ras activation and triggers a Ras signal that attenuates ERK but not phosphoinositide 3-kinase activity. J Biol Chem. 2004;279(33):34922-30.

97. Shalom-Feuerstein R, Cooks T, Raz A, Kloog Y. Galectin-3 regulates a molecular switch from N-Ras to K-Ras usage in human breast carcinoma cells. Cancer Res. 2005;65(16):7292-300.

98. Yoshii T, Inohara H, Takenaka Y, Honjo Y, Akahani S, Nomura T, et al. Galectin-3 maintains the transformed phenotype of thyroid papillary carcinoma cells. Int J Oncol. 2001;18(4):787-92.

99. Takenaka Y, Inohara H, Yoshii T, Oshima K, Nakahara S, Akahani S, et al. Malignant transformation of thyroid follicular cells by galectin-3. Cancer Lett. 2003;195(1):1119.

100. Paron I, Scaloni A, Pines A, Bachi A, Liu FT, Puppin C, et al. Nuclear localization of Galectin-3 in transformed thyroid cells: a role in transcriptional regulation. Biochem Biophys Res Commun. 2003;302(3):545-53.

101. Hsu DK, Yang RY, Pan Z, Yu L, Salomon DR, Fung-Leung WP, et al. Targeted disruption of the galectin-3 gene results in attenuated peritoneal inflammatory responses. Am J Pathol. 2000;156(3):1073-83.

102. Paz A, Haklai R, Elad-Sfadia G, Ballan E, Kloog Y. Galectin-1 binds oncogenic HRas to mediate Ras membrane anchorage and cell transformation. Oncogene. 2001;20(51):7486-93.

103. Gossen M, Bujard H. Tight control of gene expression in mammalian cells by tetracycline-responsive promoters. Proc Natl Acad Sci U S A. 1992;89(12):5547-51.

104. Chomczynski P, Sacchi N. Single-step method of RNA isolation by acid guanidinium thiocyanate-phenol-chloroform extraction. Anal Biochem. 1987;162(1):156-9. 
105. Altschul SF, Madden TL, Schaffer AA, Zhang J, Zhang Z, Miller W, et al. Gapped BLAST and PSI-BLAST: a new generation of protein database search programs. Nucleic Acids Res. 1997;25(17):3389-402.

106. Thompson JD, Gibson TJ, Plewniak F, Jeanmougin F, Higgins DG. The CLUSTAL_X windows interface: flexible strategies for multiple sequence alignment aided by quality analysis tools. Nucleic Acids Res. 1997;25(24):4876-82.

107. Fusco A, Chiappetta G, Hui P, Garcia-Rostan G, Golden L, Kinder BK, et al. Assessment of RET/PTC oncogene activation and clonality in thyroid nodules with incomplete morphological evidence of papillary carcinoma: a search for the early precursors of papillary cancer. Am J Pathol. 2002;160(6):2157-67.

108. Bantounas I, Phylactou LA, Uney JB. RNA interference and the use of small interfering RNA to study gene function in mammalian systems. J Mol Endocrinol. 2004;33(3):545-57.

109. Elbashir SM, Harborth J, Lendeckel W, Yalcin A, Weber K, Tuschl T. Duplexes of 21-nucleotide RNAs mediate RNA interference in cultured mammalian cells. Nature. 2001;411(6836):494-8.

110. Paddison PJ, Hannon GJ. RNA interference: the new somatic cell genetics? Cancer Cell. 2002;2(1):17-23.

111. Ishizaka Y, Ushijima T, Sugimura T, Nagao M. cDNA cloning and characterization of ret activated in a human papillary thyroid carcinoma cell line. Biochem Biophys Res Commun. 1990;168(2):402-8.

112. Kent WJ. BLAT--the BLAST-like alignment tool. Genome Res. 2002;12(4):656-64.

113. Simon P. Q-Gene: processing quantitative real-time RT-PCR data. Bioinformatics. 2003;19(11):1439-40.

114. Bradford MM. A rapid and sensitive method for the quantitation of microgram quantities of protein utilizing the principle of protein-dye binding. Anal Biochem. 1976;72:248-54.

115. Costamagna E, Garcia B, Santisteban P. The functional interaction between the paired domain transcription factor Pax8 and Smad3 is involved in transforming growth factor-beta repression of the sodium/iodide symporter gene. J Biol Chem. 2004;279(5):3439-46.

116. Ortiga-Carvalho TM, Polak J, McCann S, Pazos-Moura CC. Effect of thyroid hormones on pituitary neuromedin $\mathrm{B}$ and possible interaction between thyroid hormones and neuromedin B on thyrotropin secretion. Regul Pept. 1996;67(1):47-53. 
117. Kimura ET, Kopp P, Zbaeren J, Asmis LM, Ruchti C, Maciel RM, et al. Expression of transforming growth factor beta1, beta2, and beta3 in multinodular goiters and differentiated thyroid carcinomas: a comparative study. Thyroid. 1999;9(2):119-25.

118. Fagin JA. Minireview: branded from the start-distinct oncogenic initiating events may determine tumor fate in the thyroid. Mol Endocrinol. 2002;16(5):903-11.

119. Jung HS, Kim DW, Jo YS, Chung HK, Song JH, Park JS, et al. Regulation of protein kinase B tyrosine phosphorylation by thyroid-specific oncogenic RET/PTC kinases. Mol Endocrinol. 2005;19(11):2748-59.

120. van Weeren PC, de Bruyn KM, de Vries-Smits AM, van Lint J, Burgering BM. Essential role for protein kinase $\mathrm{B}$ (PKB) in insulin-induced glycogen synthase kinase 3 inactivation. Characterization of dominant-negative mutant of PKB. J Biol Chem. 1998;273(21):13150-6.

121. Cohen P, Frame S. The renaissance of GSK3. Nat Rev Mol Cell Biol. 2001;2(10):76976.

122. Espada J, Perez-Moreno M, Braga VM, Rodriguez-Viciana P, Cano A. H-Ras activation promotes cytoplasmic accumulation and phosphoinositide 3-OH kinase association of beta-catenin in epidermal keratinocytes. J Cell Biol. 1999;146(5):96780.

123. Park $\mathrm{CH}$, Hahm ER, Park S, Kim HK, Yang CH. The inhibitory mechanism of curcumin and its derivative against beta-catenin/Tcf signaling. FEBS Lett. 2005;579(13):2965-71.

124. Nascimento MC, Bisi H, Alves VA, Longatto-Filho A, Kanamura CT, Medeiros-Neto G. Differential reactivity for galectin-3 in Hurthle cell adenomas and carcinomas. Endocr Pathol. 2001;12(3):275-9.

125. Guttmacher A, Collins F, Drazen J. Genomic Medicine: Articles from the New England Journal of Medicine. Baltimore: The Jonhs Hopkins University Press 2004.

126. Missero C, Di Cunto F, Kiyokawa H, Koff A, Dotto GP. The absence of p21Cip1/WAF1 alters keratinocyte growth and differentiation and promotes ras-tumor progression. Genes Dev. 1996;10(23):3065-75.

127. Mitchell KO, El-Deiry WS. Overexpression of c-Myc inhibits p21WAF1/CIP1 expression and induces S-phase entry in 12-O-tetradecanoylphorbol-13-acetate (TPA)sensitive human cancer cells. Cell Growth Differ. 1999;10(4):223-30.

128. Givol I, Givol D, Rulong S, Resau J, Tsarfaty I, Hughes SH. Overexpression of human p21waf1/cip1 arrests the growth of chicken embryo fibroblasts transformed by individual oncogenes. Oncogene. 1995;11(12):2609-18. 
129. Bassen R, Brichory F, Caulet-Maugendre S, Delaval P, Dazord L. [Vertebrate galectins: structure and function, role in tumoral process]. Bull Cancer. 2000;87(10):703-7.

130. Osaki M, Oshimura M, Ito H. PI3K-Akt pathway: its functions and alterations in human cancer. Apoptosis. 2004;9(6):667-76.

131. Matsuo SE, Ebina KN, Kulcsar MA, Friguglietti CU, Kimura ET. Activin betaB expression in rat experimental goiter and human thyroid tumors. Thyroid. 2003;13(3):239-47.

132. Kimura ET, Matsuo SE, Ricarte-Filho JC. [TGFbeta, activin and SMAD signalling in thyroid cancer]. Arq Bras Endocrinol Metabol. 2007;51(5):683-9. 